Article

\title{
Analysis and Design of a ZVT Resonant Boost Converter Using an Auxiliary Resonant Circuit
}

\author{
Hee-Jun Lee and Young-Ho Kim * \\ Department of Electrical and Computer Engineering, Sungkyunkwan University, Suwon 16419, Korea; \\ jun9489@gmail.com \\ * Correspondence: toemtio@gmail.com; Tel.: +82-10-7124-5378
}

Received: 2 April 2019; Accepted: 22 April 2019; Published: 25 April 2019

\begin{abstract}
In this paper, a new zero voltage transition (ZVT) resonant boost converter is proposed. A typical boost converter generates switching losses at turning on and turning off, and these losses cause a reduction in the efficiency of the whole system. This proposed ZVT resonant boost converter utilizes a soft switching method, using an auxiliary circuit with a resonant inductor, capacitor, and two auxiliary switches. Therefore, it can reduce switching losses more so than the conventional hard switching converter. Also, the conduction period of the resonant inductor current is reduced by using a modified circuit. An experiment is conducted with the converter, which steps up the voltage from $200 \mathrm{~V}$ to $380 \mathrm{~V}$ and its switching frequency and output power are $30 \mathrm{kHz}$ and $4 \mathrm{~kW}$, respectively. It is confirmed that the experimental results and simulation results are the same and the validity of this proposed converter is verified. The conventional converter and proposed converter are analyzed by comparing the experimental results of two converters under the same conditions. It is confirmed that all switches can achieve soft switching and the proposed converter improves on the conventional converter by measuring the efficiency of two converters.
\end{abstract}

Keywords: zero voltage transition; boost converter; soft switching; auxiliary resonant circuit; zero voltage switching; zero current switching

\section{Introduction}

There has been an increase in the interest of using renewable energy sources to replace fossil fuels in order to resolve problems related to environmental destruction and to combat climate change and extreme weather trends that may be caused by environmental and air pollution that have resulted from recent rapid industrialization [1,2].

Various potential sources of alternate energy, including solar, wind, tidal, and hydrogen energy, have been the subject of intensive research. One of the disadvantages of using fuel cells and photovoltaic solar cells is that they have very low efficiency. Thus, it is very important to improve the efficiency of power conversion systems. As a result, much research has been undertaken to improve the efficiency of DC-DC converters [3-5].

A high switching frequency is required in the design of DC-DC converters that have a compact [6-8]. Non-ideal switching elements in hard switching converters cause switching losses because voltage and current are superimposed during switching and the higher the switching frequency, the greater the switching losses. These losses can be reduced through the use of soft switching. Many research papers on soft-switched resonant DC-DC converters with zero voltage switching (ZVS) and zero current switching (ZCS) techniques have been published, and several techniques that reduce switching losses have been proposed $[9,10]$. A Zero Current Transition (ZCT) converter can achieve ZCS using an auxiliary circuit, where the resonance conditions are not affected by variations in the load [11]. But the switching losses occur during the ZCT turn-off by the reverse recovery current. The current stress 
of the main switch and the conduction losses increase, since part of the current through the resonant inductor flow through the main switch. A zero voltage transition (ZVT) converter has an advantage where ZVS and ZCS can be achieved for a wide load range by using an auxiliary circuit [12-14].

A ZVT converter is used with a resonant inductor and capacitor to satisfy the ZVT condition. A resonant inductor through current is a reactive current because the resonance energy does not have a significant effect on the output and a resonant inductor is high current because the resonant current and the reactive current are the same. Thus, a highly resonant current increases losses of passive and active devices and the overall system efficiency is reduced.

In a conventional converter, the resonant inductor current flows continuously through the auxiliary circuit. Thus, the proposed ZVT Boost converter has a modified resonant circuit to reduce conduction loss.

This paper proposes a resonant ZVT boost DC-DC converter that uses an auxiliary resonant circuit to reduce switching losses and to improve converter efficiency. The resonant circuit is composed of a resonant inductor, a resonant capacitor, and an auxiliary switch. The auxiliary circuit is used in this converter to implement a soft-switching method. The switch of the auxiliary circuit also performs a soft-switching method through the resonant circuit. Furthermore, the conduction period of the resonant inductor is reduced using a modified circuit. And this leads to a reduction in the switching losses and an improvement in the overall system efficiency, as compared to a conventional converter at the same frequency.

\section{Resonant Boost DC-DC Converter}

\subsection{ZVT Resonant Boost Converter}

Figure 1a shows a conventional resonant ZVT boost converter. Its auxiliary circuit is composed of a boost converter, an auxiliary switch, a resonant inductor, two resonant capacitors, and two diodes. The resonant capacitor is discharged before the current flows through the body diode. These resonant components make a partial resonant path for the main switch to perform soft switching under the ZVT, using the resonant circuit [15]. However, the freewheeling period of the resonant inductor current causes a conduction loss of the diode and resonant inductor. This causes a reduction in the whole system's efficiency.

Figure $1 \mathrm{~b}$ shows the proposed resonant ZVT boost converter. The converter is composed of a boost converter, a main inductor, two auxiliary switches, a resonant capacitor, and an auxiliary circuit with an auxiliary capacitor. The conduction period of the resonant inductor is reduced, using a modified circuit. And this leads to a reduction in the switching losses and an improvement in the overall system efficiency.

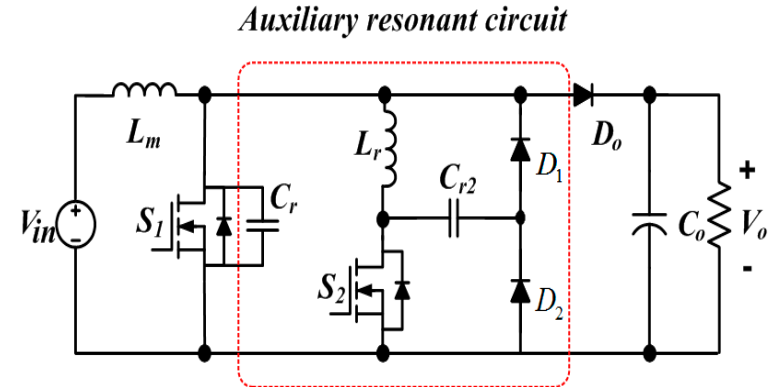

(a)

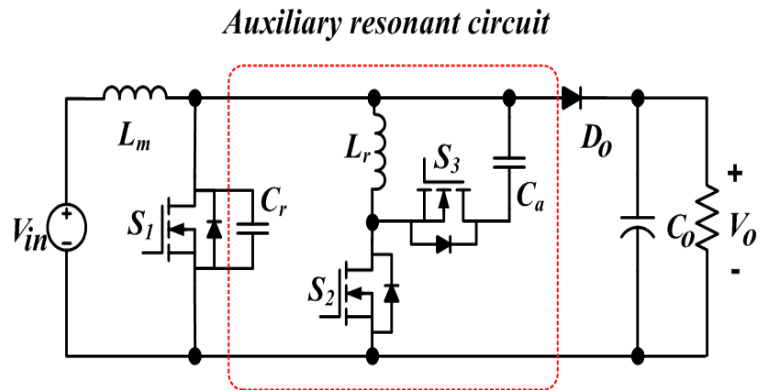

(b)

Figure 1. (a) Conventional zero voltage transition (ZVT) resonant boost converter and (b) proposed ZVT resonant boost converter. 
Figure 2 shows each waveform of the resonant inductor voltage and current for the conventional and proposed converter. The current conduction period of the proposed converter shown in Figure $2 \mathrm{~b}$ is shorter than the conventional converter shown in Figure 2a.

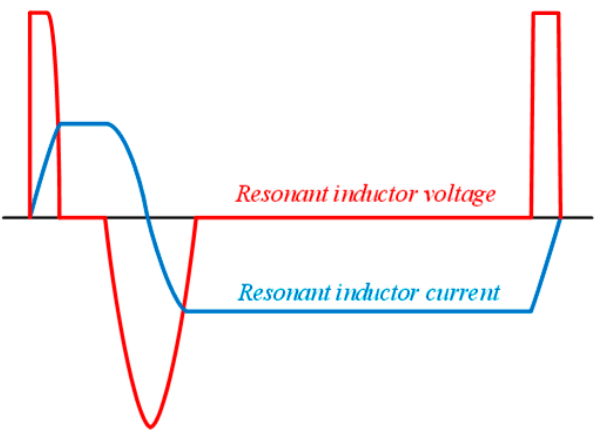

(a)

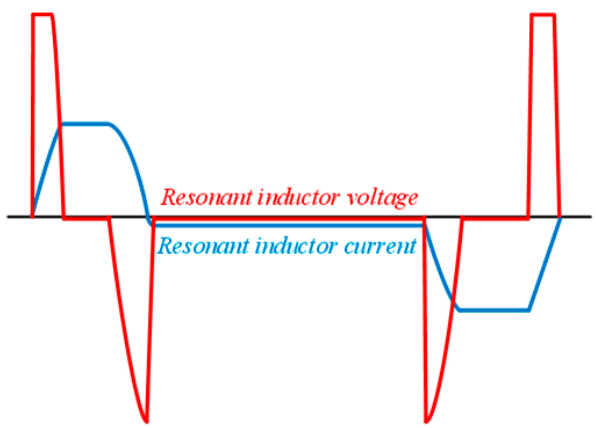

(b)

Figure 2. Comparison of resonant inductor current/voltage. (a) Conventional converter and (b) proposed converter.

\subsection{Analysis of Proposed Converter}

Operation mode of the proposed ZVT resonant boost converter is shown in Figure 3. The operational principle of the proposed converter is divided into ten modes for simple analysis. The mode 1 , mode 2 and mode 10 are discharging mode of the proposed ZVT boost converter. The mode 4 made to satisfy the ZVT condition of the main switch $S_{1}$. And next Mode 5 is turned on under the ZVS condition. And the main inductor charges form mode 5 to mode 9 . The mode 3 , mode 5 , mode 7 and mode 9 operate with resonance. The mode 2, mode 5 and mode 7 are turned on the soft switching of the auxiliary switches.
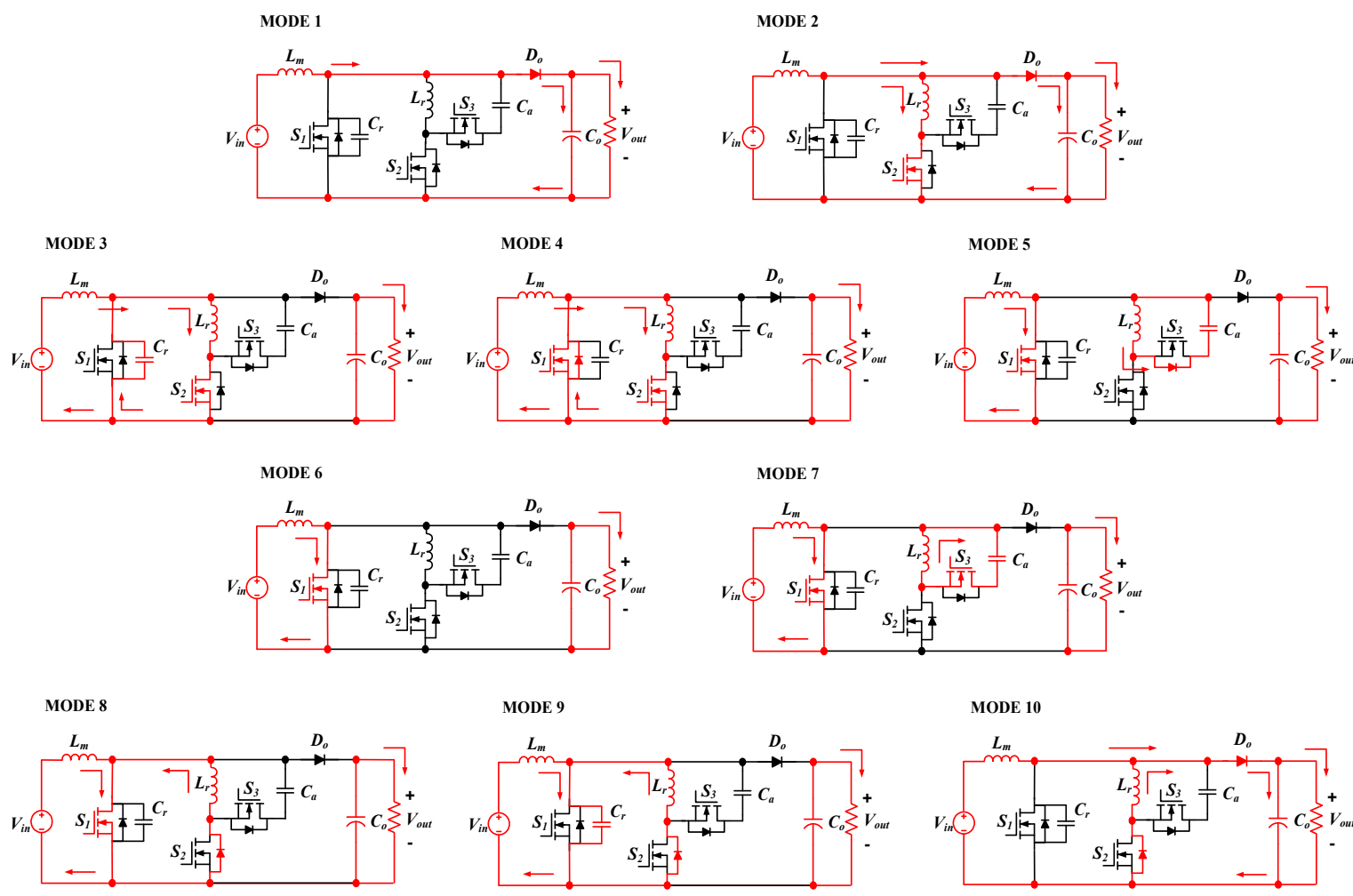

Figure 3. Operation mode of the proposed ZVT resonant boost converter.

The following statements are assumptions for simple analysis of the proposed converter: First, all switching devices and passive elements (inductor and capacitor) are ideal. Second, the input 
voltage $200 \mathrm{~V}$ and output voltage $380 \mathrm{~V}$ are constant. Third, the recovery time of all diodes is ignored. The resonant ZVT boost converters operate in 10 different modes, and the following assumptions were made for a steady-state analysis:

Mode $1\left(t_{0}-t_{1}\right)$ : Main $S_{1}$ and auxiliary switches $S_{2}$ and $S_{3}$ are turned off. The accumulated main inductor current $L_{m}$ is flowed through the output diode $D_{o}$. Then, output and resonant capacitors $C_{o}$ $C_{r}$ are charged the same voltage. Equivalent circuit of mode 1 and key waveform is shown in Figure 4. The equivalent circuit shows when the main inductor discharges for boost.
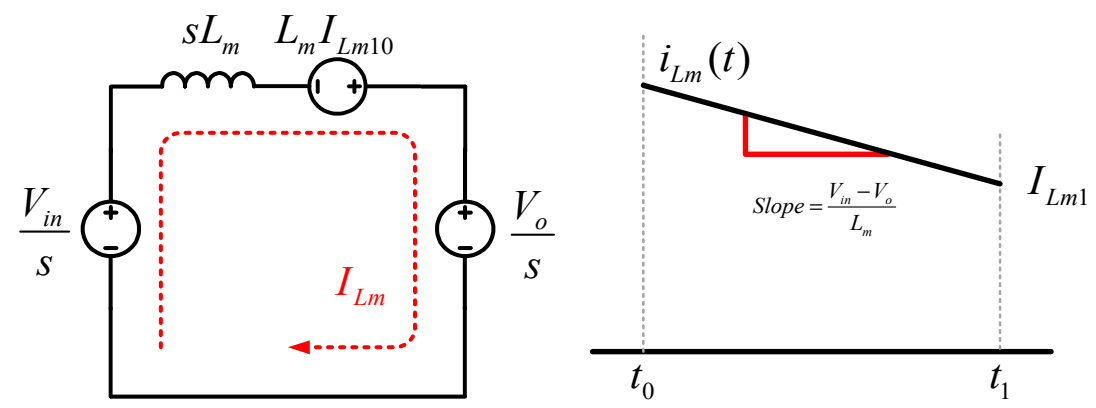

Figure 4. Equivalent circuit of Mode 1 and key waveform.

In Mode 1, the main inductor current $i_{L m}$ decreases and the resonant inductor current $i_{L r}$ and auxiliary capacitor voltage $v_{C a}$ are zero. This is expressed as the Equations (1) and (2).

$$
\begin{gathered}
i_{L m}(t)=I_{L m 10}-\frac{V_{\text {in }}-V_{o}}{L_{m}}\left(t_{0}-t_{1}\right) \\
i_{L r}(t)=0, v_{C r}(t)=V_{o}, v_{C a}(t)=0
\end{gathered}
$$

Furthermore, the main inductor current $I_{L m 1}$ is defined for the next mode $t_{2}$ analysis.

$$
i_{L m}\left(t_{1}\right)=I_{L m 1}
$$

Mode $2\left(t_{1}<t<t_{2}\right)$ : In Mode 2, an auxiliary switch $S_{2}$ turns on under the ZCS condition. The resonant inductor current $i_{L r}$ increases linearly from zero. The main inductor current $i_{L m}$ decreases. When the resonant inductor current $i_{L r}$ is equal to the main inductor current $i_{L m}$, Mode 2 is completed. Also Figure 5 shows an equivalent circuit and key waveform for analyzing mode 2. And the Equivalent circuit Indicates to calculate the magnitude of the current of main inductor $i_{L m}$ and resonant inductor $i_{L r}$. Thus, the main inductor current is equal to the minimum. The main inductor current $i_{L m}$ and resonant inductor current $i_{L r}$ are expressed by Equations (4) and (5).

$$
\begin{gathered}
i_{L m}(t)=I_{L m 1}-\frac{V_{o}-V_{i n}}{L_{m}} t, i_{L r}(t)=\frac{V_{o}}{L_{r}} t \\
i_{L m}\left(t_{2}\right)=i_{L r}\left(t_{2}\right) \approx I_{\text {min }}
\end{gathered}
$$

The resonant capacitor voltage $v_{C r}$ is equal to output voltage. If parasitic capacitance of resonant switch $S_{3}$ is ignored, auxiliary capacitor voltage $v_{C a}$ is zero.

$$
v_{C r}(t)=V_{o}, v_{C a}(t)=0
$$

For Mode 3, the resonant inductor current $I_{L r 2}$ is defined as Equation (7).

$$
i_{L r}\left(t_{2}\right)=\frac{V_{o}}{L_{r}} t=I_{L r 2}=I_{L m 2}
$$



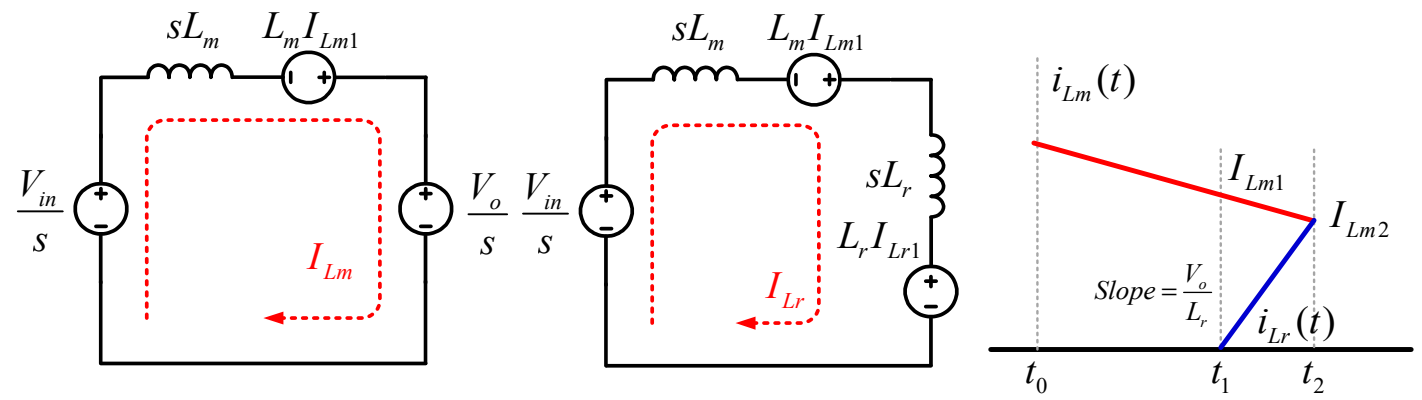

Figure 5. The equivalent circuit of Mode 2 and key waveform.

Mode $3\left(t_{2}<t<t_{3}\right)$ : When the main and resonant inductor currents $i_{L m}$ and $i_{L r}$ are equalized, the resonance operation between resonant capacitor $C_{r}$ and resonant inductor $L_{r}$ is started. Then, output diode $D_{o}$ is turned off because the resonant capacitor $C_{r}$ is discharged. Then, equivalent circuit of resonance operation is shown in Figure 6. The key waveform of mode 3 indicates main inductor current $i_{L m}$, resonant inductor current $i_{L r}$ and resonant capacitor voltage $v_{C r}$.

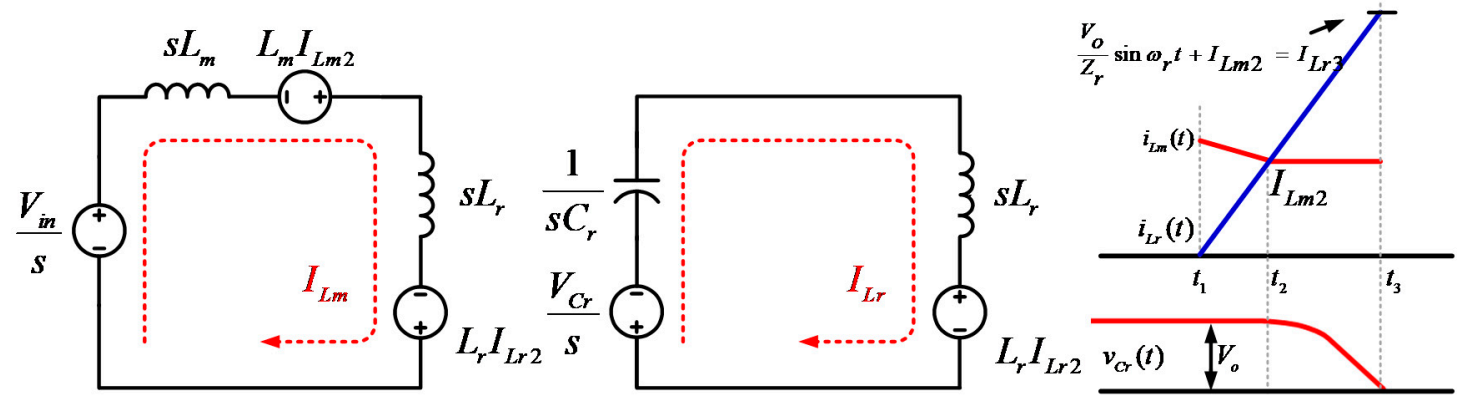

Figure 6. The equivalent circuit of Mode 3 and key waveform.

At the end of Mode 3, the resonant capacitor $C_{r}$ is equal to zero. The resonant capacitor voltage $v_{C r}$ and resonant inductor current $i_{L r}$ can be obtained by the Laplace transform, following Equations (9), (10), (12), and (13). In addition, the resonant impedance $Z_{r}$ and angular frequency $\omega_{r}$ are given by Equation (16). Additionally, $i_{L m}, i_{L r}, v_{C a}$, and $v_{C r}$ are defined by Equations (8), (11), (14), and (15).

$$
\begin{gathered}
i_{L m}(t) \approx I_{\text {min }} \\
\frac{V_{o}}{s}=\frac{i_{L r}(s)}{s C_{r}}+s L_{r} i_{L r}(s)+I_{m i n} \\
i_{L r}(s)=\frac{\frac{V_{o}}{L_{r}} \sqrt{L_{r} C_{r}} \cdot \frac{1}{\sqrt{L_{r} C_{r}}}+I_{m i n}}{s^{2}+\left(\frac{1}{\sqrt{L_{r} C_{r}}}\right)^{2}} \\
i_{L r}(t)=\frac{V_{o}}{Z_{r}} \sin \omega_{r} t+I_{m i n} \\
C_{r} V_{o}=s C_{r} v_{c r}(s)+\frac{v L_{C r}(s)}{s L_{r}} \\
v_{C r}(s)=\frac{1}{s C_{r}+\frac{1}{s L_{r}}} C_{r} V_{o} \\
=\frac{s}{s^{2}+\left(\frac{1}{\sqrt{L_{r} C_{r}}}\right)^{2}} V_{o}
\end{gathered}
$$




$$
\begin{gathered}
v_{C r}(t)=V_{o} \cos \omega_{r} t \\
v_{C a}(t)=0
\end{gathered}
$$

where

$$
\omega_{r}=\frac{1}{\sqrt{L_{r} C_{r}}}, Z_{r}=\sqrt{\frac{L_{r}}{C_{r}}}
$$

The resonant inductor current $I_{L r 3}$ is defined for the next mode $t_{4}$ analysis.

$$
i_{L r}\left(t_{3}\right)=\frac{V_{o}}{Z_{r}} \sin \omega_{r} t+I_{L r 2}=I_{L r 3}
$$

Mode $4\left(t_{3}<t<t_{4}\right)$ : The body diode of the main switch $S_{1}$ is turned on, and the voltage of main switch $S_{1}$ is equal to zero. Then, the main switch $S_{1}$ is made to satisfy the ZVT condition. Resonant current flows through the anti-parallel diode of the main switch $S_{1}$. The main inductor current $i_{L m}$ and the resonant inductor current $i_{L r}$ can be derived from Equation (18). Auxiliary and resonant capacitor voltage $v_{\mathrm{Cr}}$ are all zero by Equation (19). Thus, Figure 7 shows for derivation of the equation. And voltage and current of switches is shown in the key waveform. Mode 4 ends when the auxiliary switch $S_{2}$ is turned off.

$$
\begin{gathered}
i_{L m}(t)=\frac{V_{\text {in }}}{L_{m}} t+I_{\text {min }}, i_{L r}(t)=I_{L r 3} \\
v_{C r}(t)=0, v_{C a}(t)=0
\end{gathered}
$$
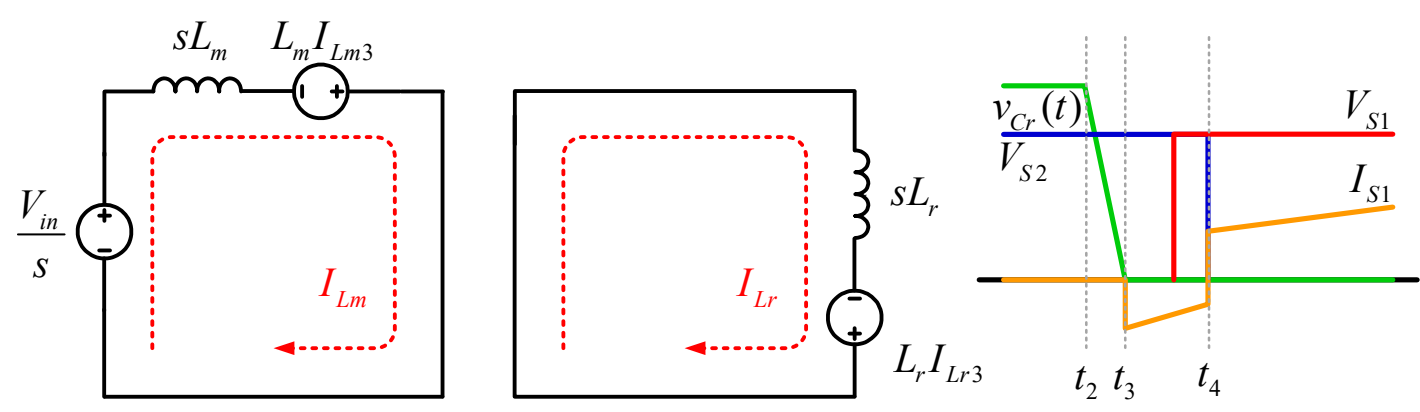

Figure 7. The equivalent circuit of Mode 4 and key waveform.

Main inductor current $I_{L m 4}$ is defined for the next mode $t_{5}$ analysis.

$$
i_{L m}\left(t_{4}\right)=\frac{V_{\text {in }}}{L_{m}} t+i_{L m 3}=I_{L m 4}
$$

Mode $5\left(t_{4}<t<t_{5}\right)$ : In Mode 5 , the main switch $S_{1}$ is turned on under the ZVS condition. Then, the main inductor current $i_{L m}$ increases linearly. The auxiliary switch $S_{2}$ is turned off in the same condition, while the second resonance is begun by the resonant inductor $L_{r}$ and auxiliary capacitor $C_{a}$. Thus, the resonant inductor current $i_{L r}$ decreases. The auxiliary capacitor voltage $v_{C a}$ and resonant inductor current $i_{L r}$ can be derived from the Laplace transform, following Equations (22), (24), and (25). At this time, the equivalent circuit of mode 5 is shown in Figure 8. The equivalent circuit is divided into main inductor current $i_{L m}$ and resonance circuit. The key waveform indicates resonant inductor current $i_{L r}$, main inductor current $i_{L m}$ and auxiliary capacitor voltage $v_{C a}$. 


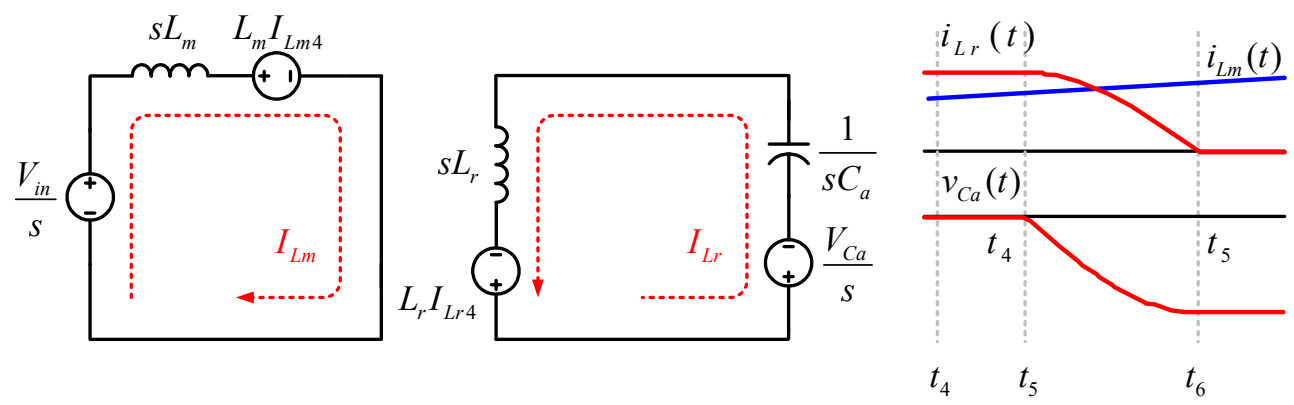

Figure 8. The equivalent circuit of Mode 5 and key waveform.

Additionally, the resonant impedance $Z_{a}$ and angular frequency $\omega_{a}$ are given by Equation (27). Then, $i_{L m}, i_{L r}, v_{c a}$, and $v_{C r}$ are defined by Equations (21), (23), and (26).

$$
\begin{gathered}
i_{L m}(t)=\frac{V_{\text {in }}}{L_{m}} t+I_{L m 4} \\
i_{L r}(s)=\frac{L_{r} I_{L r 4}}{\frac{1}{s C_{a}}+s L_{r}} \\
=\frac{s}{s^{2}+\left(\frac{1}{\sqrt{L_{r} C_{r}}}\right)^{2}} I_{L r 4} \\
i_{L r}(t)=I_{L r 4} \cos \omega_{a} t \\
\frac{I_{L r 4}}{s}=-\frac{v_{C a}}{s L_{r}}+v_{C a} s C_{a} \\
v_{C a}(s)=-\frac{\sqrt{\frac{L_{r}}{C_{a}}} \cdot \frac{1}{\sqrt{L_{r} C_{a}}}}{s^{2}+\left(\frac{1}{\sqrt{L_{r} C_{a}}}\right)^{2}} I_{L r 4} \\
v_{C a}(t)=-Z_{a} I_{L r 4} \sin \omega_{a} t
\end{gathered}
$$

where

$$
\omega_{a}=\frac{1}{\sqrt{L_{r} C_{a}}} Z_{a}=\sqrt{\frac{L_{r}}{C_{a}}}
$$

For Mode 6, the resonant inductor current $i_{L r}$ and auxiliary capacitor voltage $v_{C a}$ are defined as Equation (28).

$$
i_{L r}\left(t_{5}\right)=0=I_{L r 5}, v_{C a}\left(t_{5}\right) \approx V_{o}
$$

Mode $6\left(t_{5}<t<t_{6}\right)$ : In Mode 6, resonant inductor $L_{r}$ and auxiliary capacitor $C_{a}$ end the second resonant operation and the resonant capacitor $C_{a}$ is charged. The main inductor current $i_{L m}$ increases linearly through the main switch $S_{1}$. Mode 6 ends when the auxiliary switch $S_{3}$ turns on. The equivalent circuit of mode 6 and key waveform is shown in Figure 9. The main inductor current $i_{L m}$ can be calculated through the equivalent circuit. The $i_{L m}, i_{L r}, v_{C a}$, and $v_{C r}$ values are as follows in Equations (29) and (30):

$$
\begin{gathered}
i_{L m}(t)=\frac{V_{i n}}{L_{m}} t+I_{L m 5}, i_{L r}(t)=0 \\
v_{C a}(t)=-V_{o}, v_{C r}(t)=0
\end{gathered}
$$



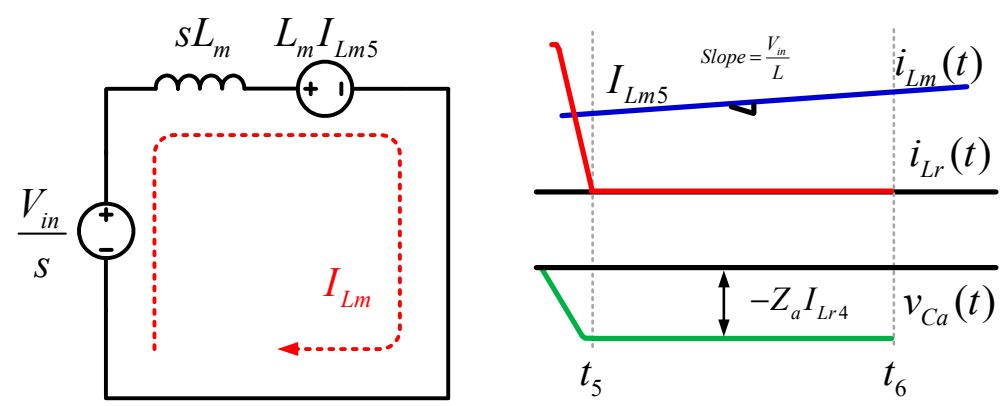

Figure 9. The equivalent circuit of Mode 6 and key waveform.

Mode $7\left(t_{6}<t<t_{7}\right)$ : At the beginning of Mode 7 , the third resonance begins. Then, the auxiliary switch $S_{3}$ turns on under the ZCS condition. The energy stored in the resonant capacitor $C_{r}$ is transferred to the resonant inductor through auxiliary switch $S_{3}$. The auxiliary capacitor voltage $v_{C a}$ and resonant inductor current $i_{L r}$ can be derived from the Laplace transform, following Equations (32), (33), (35), and (36). Then, the equivalent circuit is shown in Figure 10. Mode 7 ends when the auxiliary capacitor $C_{a}$ voltage reaches $0 \mathrm{~V}$, as in Equation (38). The current that flows through the main inductor $L_{m}$ increases linearly, as in Equation (31) and the energy is stored in the resonant inductor $L_{r}$ through the auxiliary switch $S_{3}$. The $i_{L r}$ and $v_{c a}$ values were defined by Equations (34) and (37).

$$
\begin{gathered}
i_{L m}(t)=\frac{V_{i n}}{L_{m}} t+I_{L m 6} \\
-\frac{Z_{a} I_{L r 4}}{s}=\frac{i_{L r}(s)}{s C_{a}}+s L_{r} i_{L r}(s) \\
i_{L r}(s)=\frac{-\frac{Z_{a} I_{L r 4}}{L_{r}} \cdot \sqrt{L_{r} C_{a}} \cdot \frac{1}{\sqrt{L_{r} C_{a}}}}{s^{2}+\left(\frac{1}{\sqrt{L_{r} C_{a}}}\right)^{2}} \\
i_{L r}(t)=-I_{L r 4} \sin \omega_{a} t \\
C_{a} Z_{a} I_{L r 4}=v_{C a}(s) s C_{a}+\frac{v_{C a}(s)}{s L_{r}} \\
v_{C a}(s)=-\frac{s}{s^{2}+\left(\frac{1}{\sqrt{L_{r} C_{a}}}\right)^{2}} Z_{a} I_{L r 4} \\
v_{C a}(t)=-Z_{a} I_{L r 4} \cos \omega_{a} t \\
v_{C r}(t)=0
\end{gathered}
$$
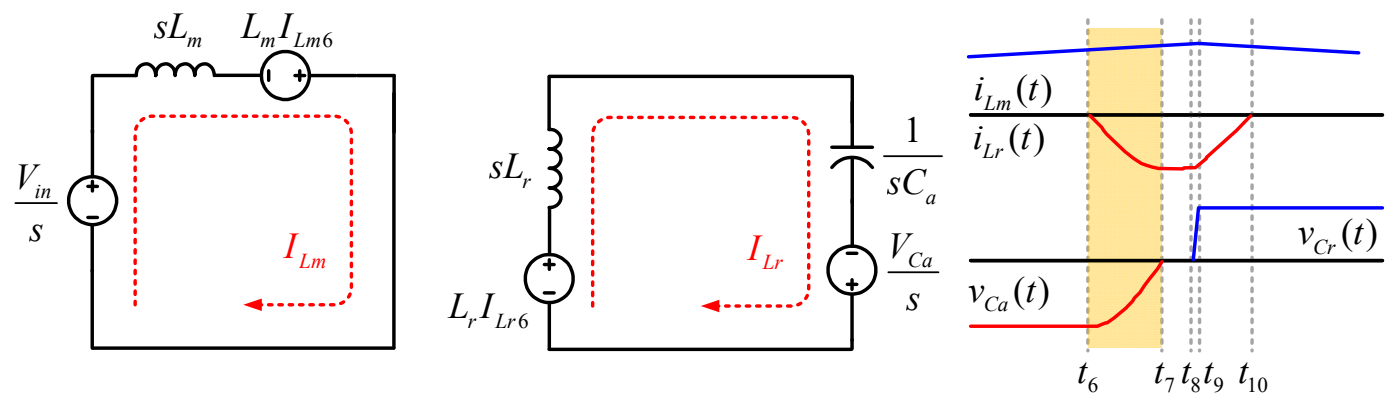

Figure 10. The equivalent circuit of Mode 7 and key waveform. 
Mode $8\left(t_{7}<t<t_{8}\right)$ : In Mode 8 , the auxiliary capacitor voltage $v_{C a}$ becomes zero. Then, the main inductor current $i_{L m}$ increases linearly and the body diode of the auxiliary switch $S_{2}$ is turned on. The resonant inductor $L_{r}$ current flows through the freewheeling path of the body diode- the main switch $S_{1}$. When the main switch $S_{1}$ is turned off, Mode 8 is complete. In this interval, the magnitude of the resonant inductor current $i_{L r}$ is equal to that of Mode 3. However, the current flow is reversed. The $i_{L m}, i_{L r}, v_{C a}$, and $v_{C r}$ values are as follows in Equations (39) and (40):

$$
\begin{gathered}
i_{L m}(t)=I_{L m 7}+\frac{V_{i n}}{L} t, i_{L r}\left(t_{8}\right)=i_{L r 7} \\
v_{C a}(t)=0, v_{C r}(t)=0
\end{gathered}
$$

The equivalent circuit of mode 8 and key waveform is shown Figure 11. The equivalent circuit is divided into main inductor current $i_{L m}$ and resonant inductor current $i_{L r}$. The key waveform indicates $i_{L m}, i_{L r}, v_{C a}$, and $v_{C r}$.
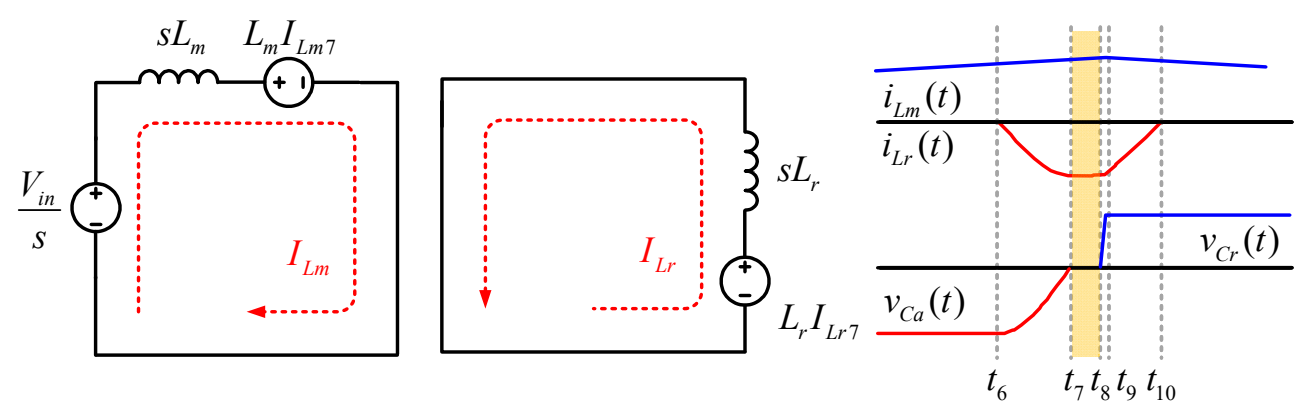

Figure 11. The equivalent circuit of Mode 8 and key waveform.

For Mode 9, the main and resonant current $I_{L m 8}$ are defined by Equations (41) and (42).

$$
\begin{gathered}
i_{L m}\left(t_{8}\right)=\frac{V_{i n}}{L_{m}} t+I_{L m 7}=I_{L m 8} \\
i_{L r}\left(t_{8}\right)=I_{L r 7}=I_{L r 8}
\end{gathered}
$$

Mode $9\left(t_{8}<t<t_{9}\right)$ : In this mode, the fourth resonance between the resonant inductor $L_{r}$ and the resonant capacitor $C_{r}$ begins. The current that flows in the resonance inductor $L_{r}$ is reduced from the maximum point and the resonant capacitor $C_{r}$ is charged by the total current of the main and resonant inductor. Then, the voltage of the resonant capacitor $v_{\mathrm{Ca}}$ is charged to the output voltage $V_{o}$, and Mode 9 ends. The resonant capacitor voltage $v_{C a}$ and resonant inductor current $i_{L r}$ can be derived from the Laplace transform, following Equations (44), (45), (47), and (48). The $i_{L m}, i_{L r}, v_{C a}$, and $v_{C r}$ values are as follows in Equations (43), (46), (49), and (50):

$$
\begin{gathered}
i_{L m}(t)=I_{L m 8} \\
-L_{r}\left(I_{L r 8}\right)=\frac{i_{L r}(s)}{s C_{r}}+i_{L r}(s) s L_{r} \\
i_{L r}(s)=-\frac{s}{s^{2}+\left(\frac{1}{\sqrt{L_{r} C_{r}}}\right)^{2}}\left(I_{L 8}\right) \\
i_{L r}(t)=I_{L 8} \cos \omega_{r} t \\
\frac{I_{L 8}}{s}=\frac{v_{C r}(s)}{s L_{r}}+v_{C r}(s) s C_{r}
\end{gathered}
$$




$$
\begin{gathered}
v_{C r}(s)=\frac{\sqrt{\frac{L_{r}}{C_{r}}} \cdot \frac{1}{\sqrt{L_{r} C_{r}}}}{s^{2}+\left(\frac{1}{\sqrt{L_{r} C_{r}}}\right)^{2}}\left(I_{L 8}\right) \\
v_{C r}(t)=Z_{r} I_{L r 8} \sin \omega_{r} t \\
v_{C a}(t)=0
\end{gathered}
$$

The Mode 9 is divided into two equivalent circuits in Figure 12. Then, the equivalent circuit of resonance operation is shown. The key waveform of Mode 9 indicates $i_{L m}, i_{L r}, v_{C a}$, and $v_{C r}$. And the key waveform of Figure 12 shows the maximum of the main inductor current $i_{L m}$.

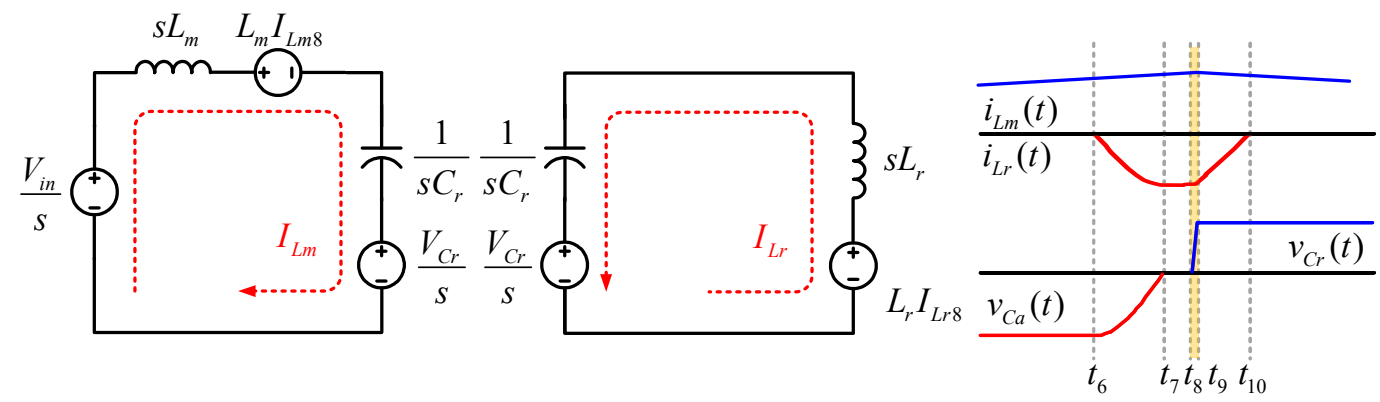

Figure 12. The equivalent circuit of Mode 9 and key waveform.

For Mode 10, the main inductor current $I_{L m 9}$ is defined:

$$
i_{L m}\left(t_{9}\right)=I_{L m 8}=I_{L m 9}
$$

Mode $10\left(t_{9}<t<t_{10}\right)$ : The resonant inductor current $i_{L r}$ linearly decreases to zero. And if the resonant capacitor voltage $v_{C a}$ is charged with a larger output than output voltage $V_{o}$, then the output diode $D_{o}$ is turned on. Mode 10 is completed, and the next switching cycle starts.

The Mode 10 is divided into two equivalent circuits in Figure 13. Then, the equivalent circuit of main inductor $L_{m}$ is shown. Other equivalent circuit indicates resonant inductor $L_{r}$. The key waveform of Figure 13 shows the maximum of the main inductor current $i_{L m}$. And resonant capacitors $C_{r}$ are charged the output voltage.

$$
\begin{gathered}
i_{L m}(t)=I_{L m 9}-\frac{V_{o}-V_{i n}}{L} t \\
i_{L r}(t)=I_{L r 9}-\frac{V_{o}}{L_{r}} t \\
v_{C r}(t)=V_{o}, v_{C a}(t)=0
\end{gathered}
$$
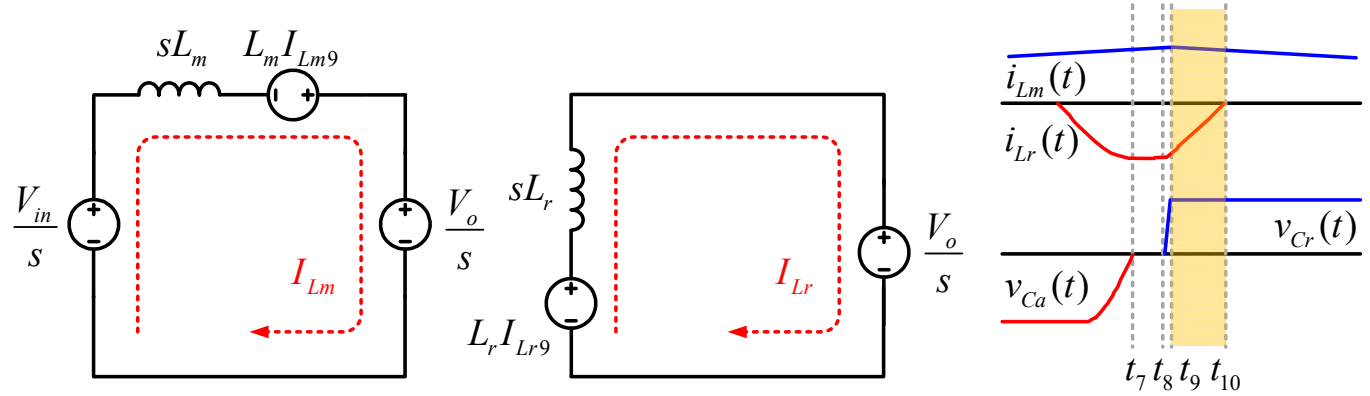

Figure 13. The equivalent circuit of Mode 10 and key waveform. 


\subsection{PWM Signal Analysis}

PWM signals of the main and auxiliary switch are shown in Figure 14. The auxiliary switch $S_{2}$ is turned on before the main switch $S_{1}$ is turned on. Then turning on interval of the auxiliary switch $S_{2}$ can be divided into mode 2, mode 3 and mode 4 . The main switch $S_{1}$ makes boost at turning on and turning off. The auxiliary switch $S_{3}$ operates to reduce conduction loss. And turning on interval of the auxiliary switch $S_{3}$ can be shown into mode 7 .

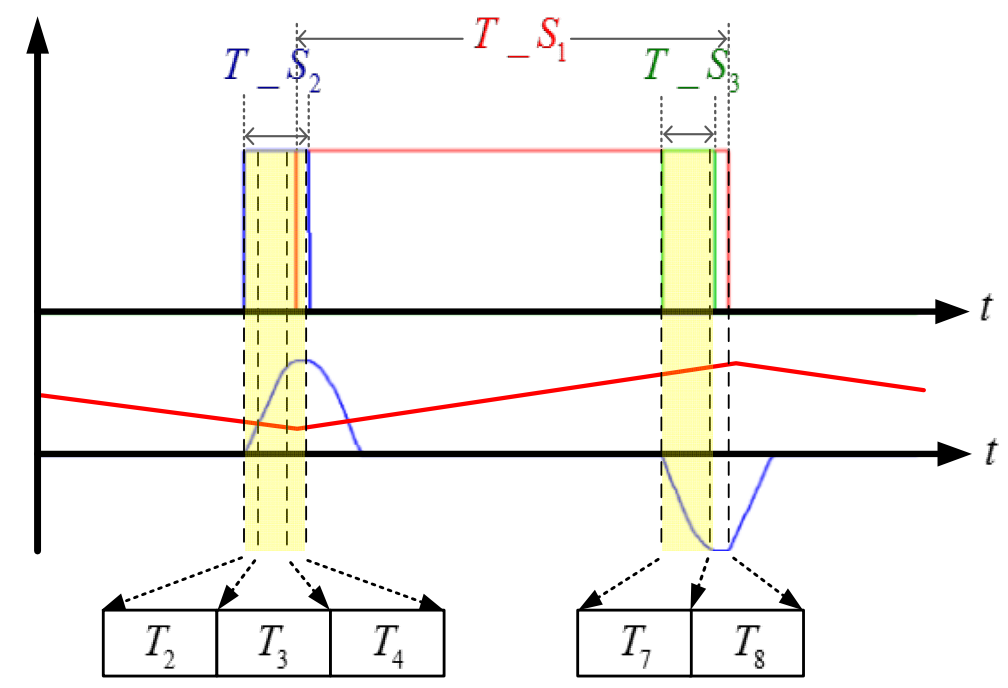

Figure 14. Pulse width modulation (PWM) signals of the main and auxiliary switch.

This design for a proposed resonant ZVT boost converter is composed of three switches, and the minimum turn-on and turn-off time should be satisfied in order to achieve ZVS and ZCS. The main switch controls the step-up ratio. Other auxiliary switches enable the main switch to operate with a soft switching. The resonances for the resonant inductor $L_{r}$ and the resonant capacitor $C_{r}$ are started by turning on the auxiliary switch $S_{2}$. When the charged energy completely discharges from the resonant capacitor, the main switch $S_{1}$ turns on in the ZVS condition. Before the main switch $S_{1}$ turns on, the auxiliary switch $S_{2}$ is turned on and turned off. To achieve the ZVS, a minimum time of auxiliary switch pulse width modulation (PWM) is required. The time is determined by Mode 2, Mode 3, and Mode 4 . The $T_{2}, T_{3}$, and $T_{4}$ time must be satisfied according to the following equation:

$$
\begin{gathered}
T_{2}=\frac{-I_{L m .1} L_{m} L_{r}}{V_{i n} L_{r}-V_{o}\left(L_{m}+L_{r}\right)} \\
T_{3}=\frac{\sin ^{-1}\left(\sin \omega_{r} t\right)}{2 \pi F_{r}} \\
F_{r}=\frac{1}{2 \pi \sqrt{L_{r} C_{r}}}
\end{gathered}
$$

$T_{4}$ is determined by using a factor of $k$ from the time delay of the switching elements.

$$
\begin{gathered}
T_{4}=t \times k \\
t<\frac{L_{m}\left(I_{L r 3}-I_{L m 3}\right)}{V_{i n}}
\end{gathered}
$$

The turning on and off times for the auxiliary switch $S_{2}$ can be satisfied, as shown in the following Equation (60):

$$
T_{S 2}>T_{2}+T_{3}+T_{4}
$$


Before the main switch is turned off, the auxiliary switch $S_{3}$ is turned on and off. After the energy for the resonant inductor $L_{r}$ discharges and reaches zero, the auxiliary switch $S_{3}$ turns on. The auxiliary switch $S_{3}$ turns on in the ZCS condition. After the auxiliary capacitor $C_{a}$ discharges, the auxiliary switch $S_{3}$ turns off in the ZVS condition. The turning on and off times for the auxiliary switch $S_{3}$ can be calculated by using the equations for Modes 7 and $8 . T_{7}$ requires a longer time than half the secondary resonant auxiliary frequency and $T_{8}$ requires a longer time than the off-delay time of the elements, which can be obtained from the manufacturer's data sheet. The shortest time for the auxiliary switch $S_{3}$ should be satisfied by using the following Equations (61)-(63).

$$
\begin{gathered}
T_{7}=\frac{T_{r}}{2}=\pi \sqrt{L_{r} C_{a}} \\
T_{8}>t_{d(o f f)} \\
T_{S 3}>T_{7}+T_{8}
\end{gathered}
$$

\subsection{Resonant Device Design}

Resonant capacitor $C_{r}$ influences the ZVS operation of the main switch $S_{1}$. The ZVS switching process can be performed when the resonant capacitor $C_{r}$ is sufficiently charged [16]. Thus, the design of resonant capacitors $C_{r}$ is important. When the resonant capacitor $C_{r}$ is charged and discharged in Mode 3 and Mode 9, the resonant time between the resonant inductor $L_{r}$ and resonant capacitor $C_{r}$ can be expressed as the following equation:

$$
T_{\text {mode3 }}=\frac{\pi}{2} \sqrt{L_{r} C_{r}}
$$

In Mode 9, resonant capacitor $C_{r}$ is charged to output voltage and can be expressed as the following equation:

$$
T_{\text {mode } 9}=C_{r} \frac{V_{o}}{2 I_{\text {in_max }}}
$$

Assume that the maximum current of the resonant inductor is $I_{\text {in_max }}$, and the sum of the two inductor currents is the charging current of the resonant capacitor $C_{r}$. When Mode 9 is longer than Mode 3, the defective duty ratio is lower. Thus, the time is chosen as $0.1 T_{s}$. The sum of Mode 3 and Mode 9 is selected as $1 / 10$ of one cycle. The charging time of the resonant capacitor $C_{r}$ must be longer for ZVS of the main switch. For this reason, the value of the resonant capacitor $C_{r}$ should be chosen to be 15 times larger than that of the output switch capacitor. According to the output capacitance of main switch $S_{1}$, a suitable value of the resonant capacitor is $0.6 \mathrm{nF}$. The output capacitance of the main switch $S_{1}$ is given in the manufacturer's data sheet. As a result, resonant capacitor $C_{r}$ used $10 \mathrm{nF}$ to consider a margin of error.

$$
\frac{\pi}{2} \sqrt{L_{r} C_{r}}+C_{r} \frac{V_{o}}{2 I_{\text {in_max }}} \leq 0.1 T_{\mathcal{S}}
$$

In addition, the resonant current between the resonant inductor $L_{r}$ and resonant capacitor $C_{r}$ charges the auxiliary capacitor $C_{a}$. The resonant time between the resonant inductor $L_{r}$ and auxiliary capacitor $C_{a}$ in Mode 5 and Mode 7 is set as one-fifth of the total turning on time. If the charging voltage of this resonant capacitor $C_{r}$ is too large, it may be voltage stress. The auxiliary capacitance was calculated to be $39 \mathrm{nF}$. The auxiliary capacitor used $40 \mathrm{nF}$ to consider a margin of error.

Resonance between resonant inductor $L_{r}$ and capacitor $C_{r}$ operates for soft switching of the main switch. Then, the main switch $S_{1}$ has satisfied the ZVT condition. Resonance design is very important to satisfy ZVS, ZCS, and ZVT [17]. But if the resonant inductor current $i_{L r}$ continues to increase linearly, the magnetic flux of the inductor is saturated [18]. Thus, the flux of the inductor must be prevented from reaching saturation, using the auxiliary capacitor $C_{a}$. The auxiliary capacitor $C_{a}$ is charged from the negative current of the resonant inductor. In this case, energy relation can be defined by auxiliary 
capacitor $C_{a}$ and resonant inductor $L_{r}$. Therefore, stored energy of the inductor is equal to or greater than the stored energy of the capacitor.

The resonant capacitor $L_{r}$ must charge below the output voltage $V_{o}$. Obtained values in each mode can be expressed by the following Equations (67) and (68) [19-21]:

$$
\begin{gathered}
\frac{1}{2} L_{r} I_{L r_{-} \text {max }}^{2} \geq \frac{1}{2} C_{a} V_{o}^{2} \\
C_{a} \leq \frac{L_{r} I_{L r_{-} \max }^{2}}{V_{o}^{2}}
\end{gathered}
$$

\section{Simulation Results}

The computer was simulated to verify the operation of the new ZVT boost converter design. The design specifications of the elements used in the simulation are shown in Table 1 . This paper tested the proposed converter by POWERSIM Inc. PSim9.2 software. The simulation time step has 1E-007 for detailed waveform analysis. The design specifications of the elements used in the simulation are shown in Table 1. The simulation was performed under a 30-kHz switching frequency and a 200-380 V voltage.

Table 1. Parameter of the proposed zero voltage transition (ZVT) converter.

\begin{tabular}{cccccc}
\hline Parameter & Symbol & Value & Parameter & Symbol & Value \\
\hline Input Voltage & $V_{i n}$ & $200 \mathrm{~V}$ & Main Inductor & $L_{m}$ & $1 \mathrm{mH}$ \\
Output Voltage & $V_{o}$ & $380 \mathrm{~V}$ & Resonant Inductor & $L_{r}$ & $35 \mathrm{uH}$ \\
Rated Power & $P$ & $4 \mathrm{~kW}$ & Resonant Capacitor & $C_{r}$ & $10 \mathrm{nF}$ \\
Switching Frequency & $f_{s}$ & $30-\mathrm{kHz}$ & Auxiliary Capacitor & $C_{a}$ & $40 \mathrm{nF}$ \\
\hline
\end{tabular}

The waveform of each PWM signal is shown in Figure 15 and the resonant inductor current $i_{L r}$ flows according to each PWM signal.

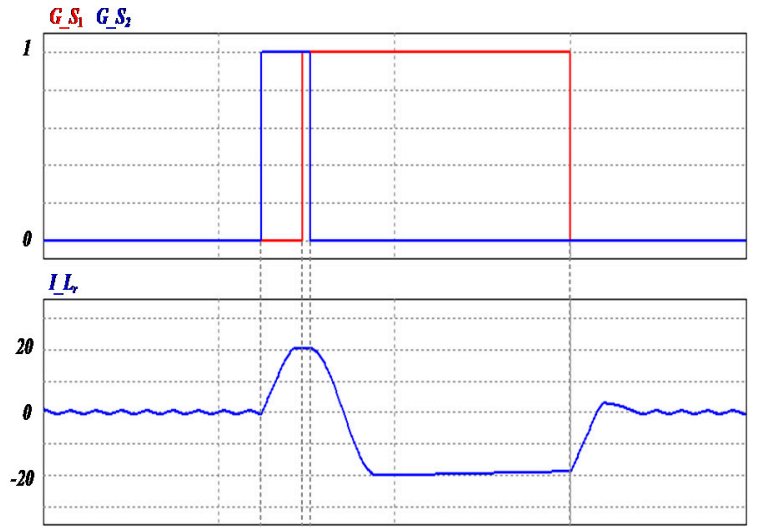

(a)
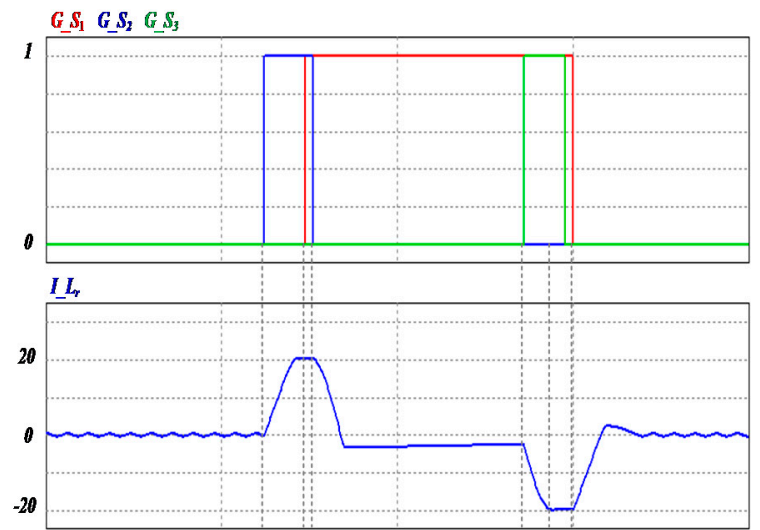

(b)

Figure 15. Waveforms of PWM signal and resonant inductor current. (a) Conventional converter and (b) proposed converter.

The current conduction period of the proposed converter is shorter than the conventional converter. The waveforms of the voltage and current of each switch are shown in Figure 16. The soft switching operations of each switch were successfully performed, as shown in Figure 16b. It also shows some voltage ringing, due to the resonance between the auxiliary switches $S_{2}$ and $S_{3}$. The switch used in the simulation is non-ideal, and the parasitic capacitances may cause a switch failure. Specifically, the output capacitance resonates with the resonance inductor and leads to ringing. These resonances 
may cause the current or voltage stress on the devices and finally increase the voltage rating of the devices.

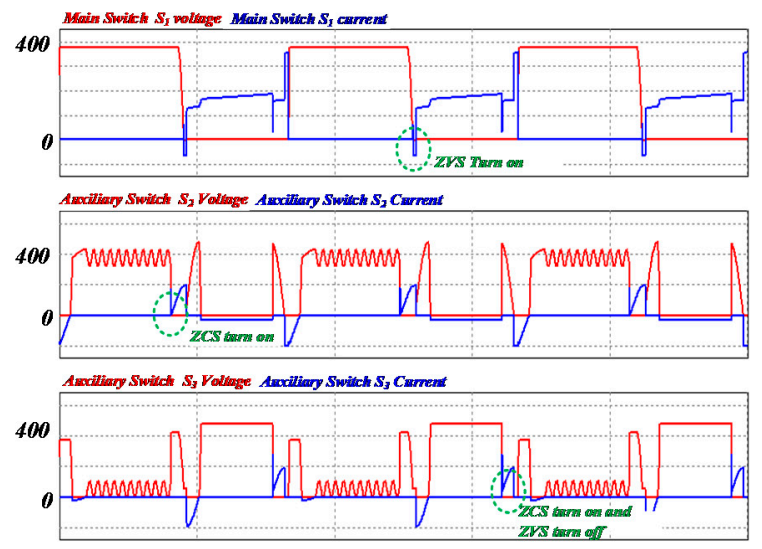

(a)
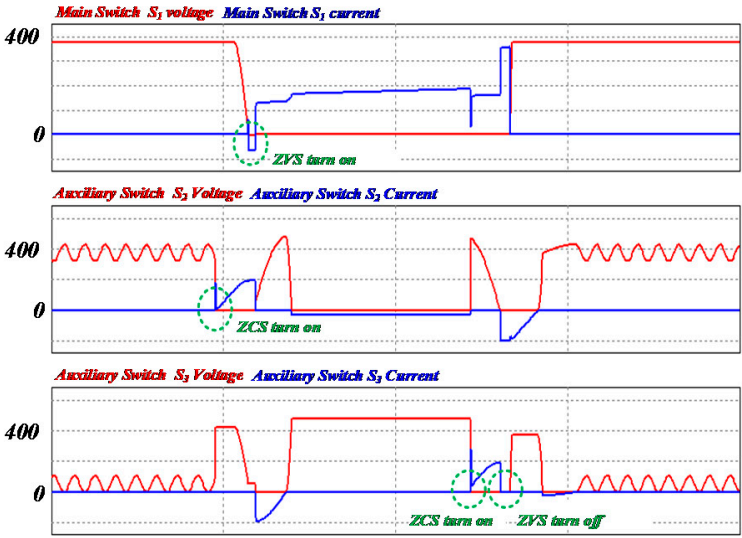

(b)

Figure 16. (a) Waveforms of voltage and current of each switch and (b) expansion waveforms.

Figure 17 shows the waveforms of the input and output of the voltage and current. The proposed ZVT boost converter can be applied to the photovoltaic system of DC distribution. Therefore, the output of the proposed converter can be directly connected to the DC voltage of the DC distribution building.

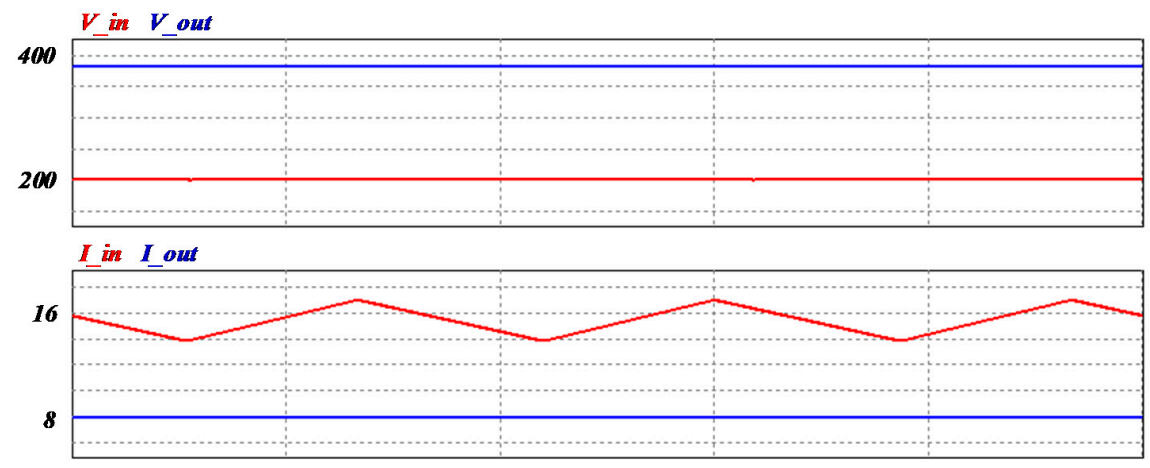

Figure 17. Waveforms of input/output voltage and current.

\section{Experimental Results}

In order to prove the theoretical analysis, experiments were conducted on the proposed ZVT boost converter in Figure 18. It consists of a boost converter, a controller, and a gate driver. The controller used in this experiment was the DSP TMS320F28335 from TI.

The experiment was conducted with the $4 \mathrm{~kW}, 30 \mathrm{kHz}$ converter, which steps up the voltage from $200 \mathrm{~V}$ to $380 \mathrm{~V}$.

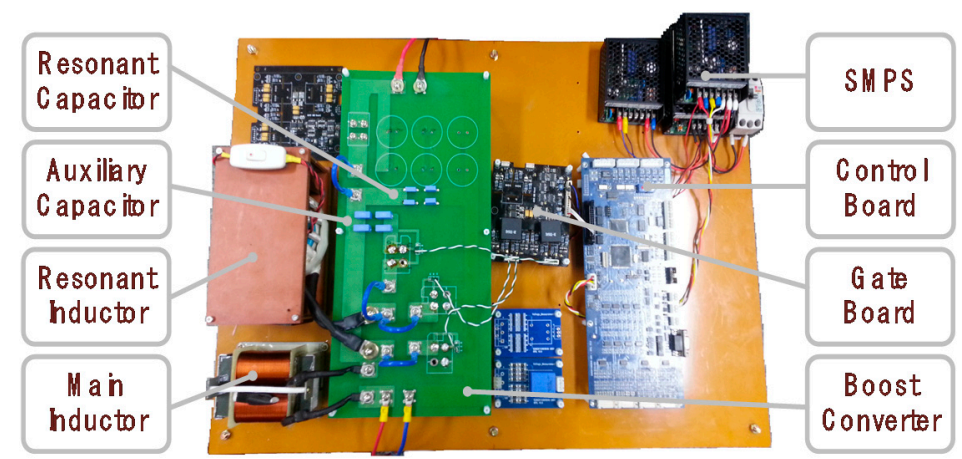

Figure 18. Experimental setup. 
To compare the conventional and the proposed converter, current waveforms of the main inductor and the resonant inductor are shown in Figure 19. When the main switch $S_{1}$ is turned on, the current through the main inductor $L_{m}$ increases linearly. When the main switch $S_{1}$ is turned off, the energy that was stored in the main inductor $L_{m}$ is released through the output diode $D_{o}$ and is transferred to the load. The same kinds of waveforms are shown in Figure 2. Conduction periods of the conventional converter were observed to be larger than those for the proposed converter.

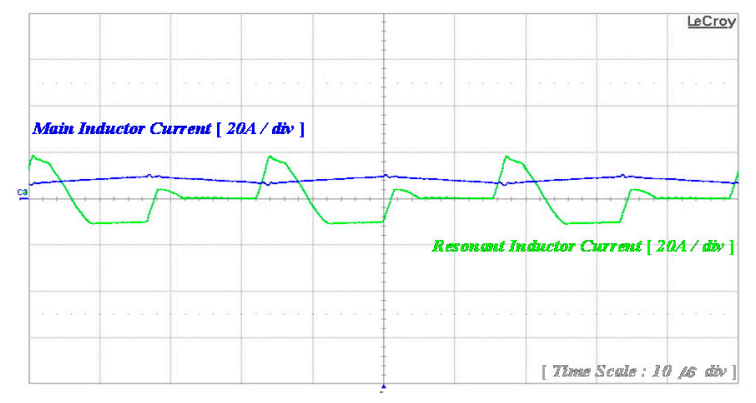

(a)

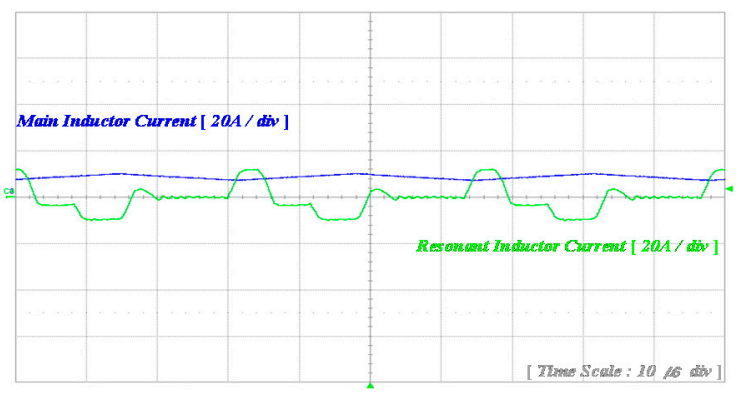

(b)

Figure 19. Waveforms of main and resonant inductor current. (a) Conventional converter and (b) proposed converter.

The waveforms for the voltage and current across the main switch $S_{1}$ are shown in Figure 20. Before the main switch $S_{1}$ is turned on, the body diode of the main switch has a freewheeling period. Then, the main switch is turned on under ZVS in the ZVT condition. The waveforms for the voltage and current across the main switch $S_{1}$ are shown in Figure 20. Figure 20b is a close up of the soft switching in voltage and current of the main switch $S_{1}$.

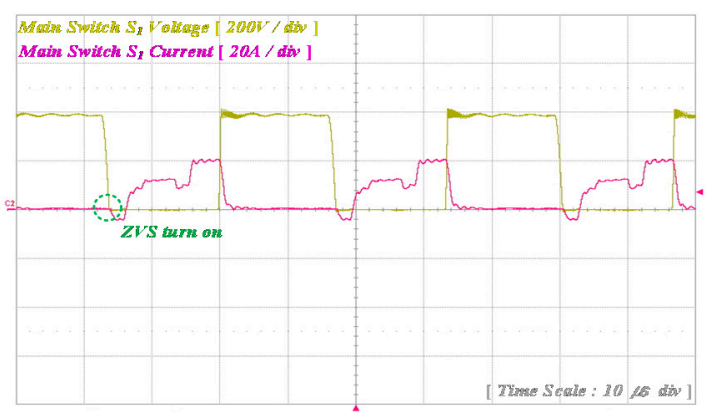

(a)

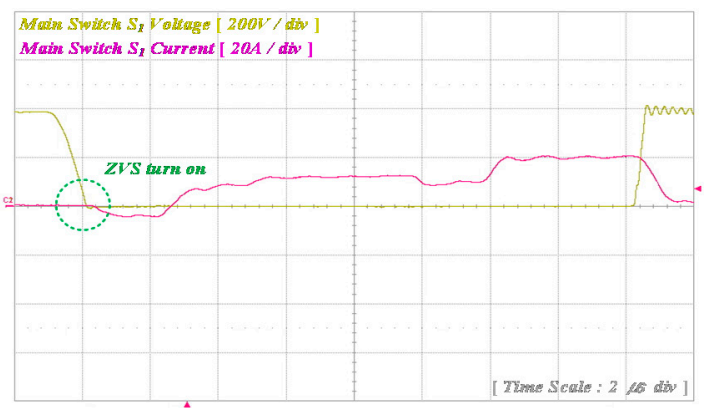

(b)

Figure 20. (a) Waveforms of main switch $S_{1}$ voltage and current and (b) expansion waveforms of $S_{1}$.

The waveforms for the voltage and the current across the auxiliary switch $S_{2}$ are shown in Figure 21. The auxiliary switch $S_{2}$ is turned on under the ZCS condition because of the resonant inductor. Thus, the current of the auxiliary switch $S_{2}$ increases linearly from zero. The voltage of the auxiliary switch $S_{2}$ is equal to zero and the auxiliary capacitor $C a$ does not affect the auxiliary switch $S_{2}$. Thus, the waveforms of the auxiliary switch $S_{2}$ are shown by a negative resonant inductor auxiliary capacitor and a resonant operation. Figure $21 \mathrm{~b}$ shows an extension of the soft switching of the auxiliary switch $S_{2}$. 


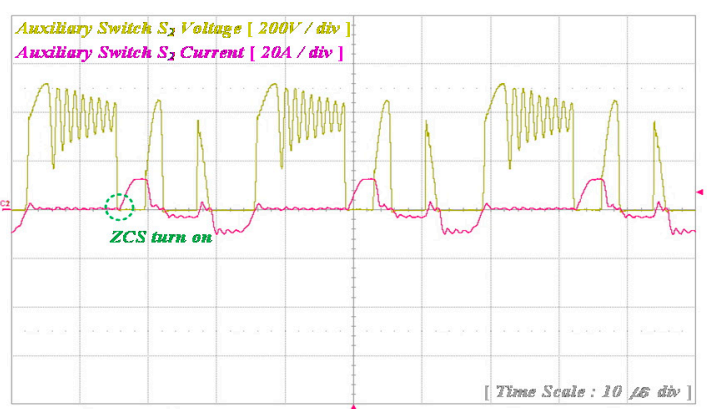

(a)

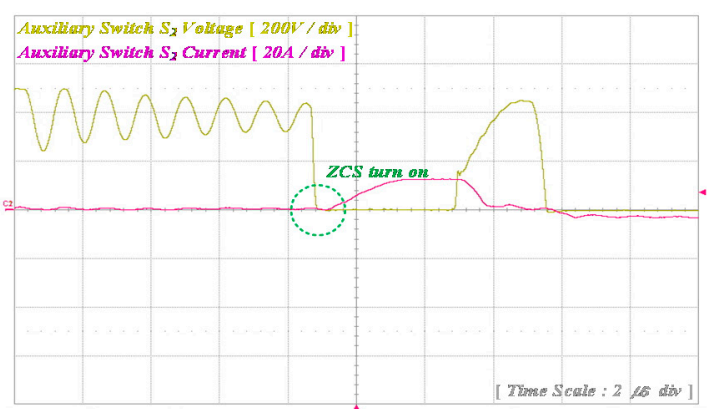

(b)

Figure 21. (a) Waveforms of auxiliary switch $S_{2}$ voltage and current and (b) expansion waveforms of $S_{2}$.

Figure 22 shows the waveforms for the voltage and current across the auxiliary switch $S_{3}$. The body diode of the main switch is turned on under a zero-voltage switching condition. Afterwards, the auxiliary switch $S_{3}$ is turned on under the ZCS condition because of the resonant inductor $L_{r}$ and auxiliary capacitor $C_{a}$. Then, voltage of the auxiliary switch $S_{3}$ remains at zero. Figure 22b shows the extension of soft-switching for the auxiliary switch $S_{3}$. Voltage ringing occurs due to the resonance between the auxiliary switches $S_{2}$ and $S_{3}$. The switch used in the simulation is non-ideal, and the parasitic capacitances may cause a switch failure. Specifically, the output capacitance resonates with the resonance inductor and leads to ringing.

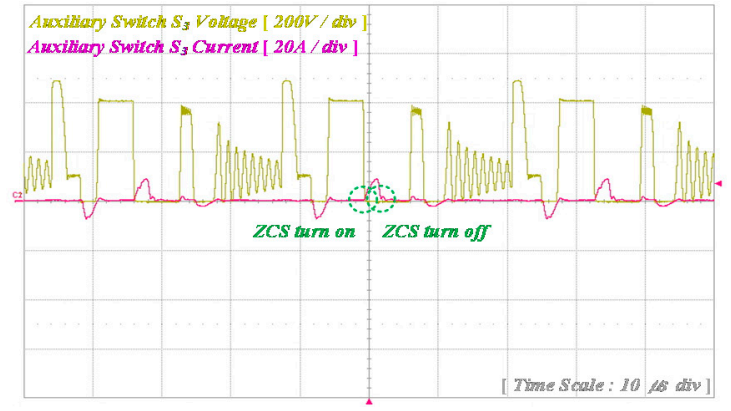

(a)

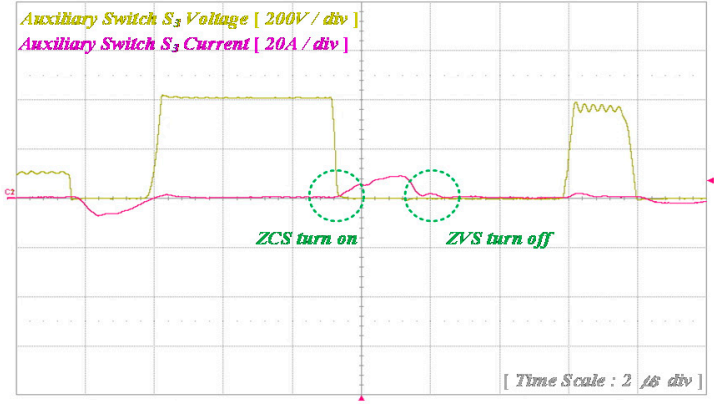

(b)

Figure 22. (a) Waveforms of auxiliary switch $S_{3}$ voltage and current and (b) expansion waveforms of $S_{3}$.

The input/output voltage and current waveforms are shown in Figure 23. A voltage step-up occurs from an input voltage of $200 \mathrm{~V}$ to an output voltage of $380 \mathrm{~V}$, indicating good control of the output voltage.

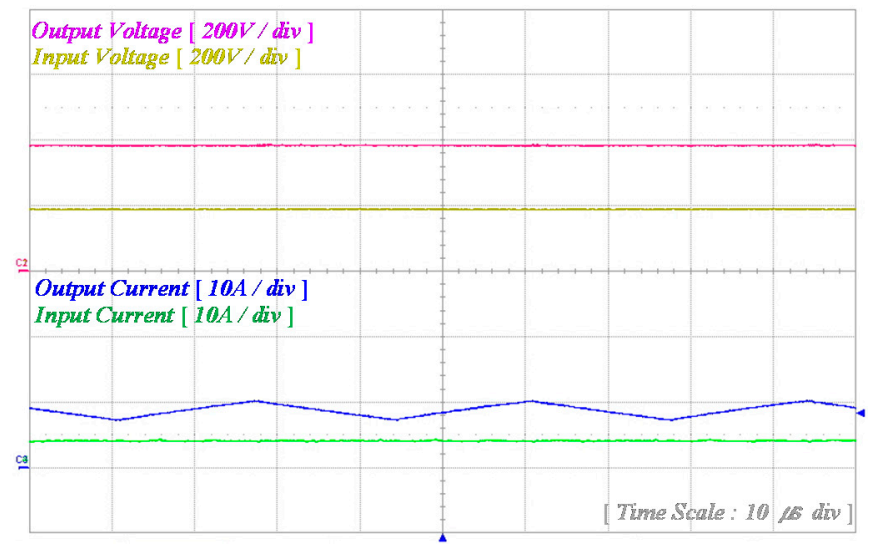

Figure 23. Waveforms of input/output voltage and current. 
The efficiency comparison of the conventional $(\mathrm{C})$ and proposed $(\mathrm{P})$ converter is shown in Table 2. A power analyzer (model WT-3000) was used to confirm the efficiency of the proposed converter. The output power $380 \mathrm{~V}$ and the input power $200 \mathrm{~V}$ were fixed while measuring variable loads, based on a rated capacity of $4 \mathrm{~kW}$. According to the efficiency measurements, a measured full-load efficiency of over $90 \%$ was confirmed, and a maximum efficiency of $96.5 \%$ was measured at $95 \%$ load.

Table 2. Efficiency comparison of conventional and proposed converter.

\begin{tabular}{ccccccccc}
\hline \multicolumn{2}{c}{$\begin{array}{c}\text { Load } \\
{[\%]}\end{array}$} & $\begin{array}{c}\mathbf{V}_{\text {in }} \\
\text { [V] }\end{array}$ & $\begin{array}{c}\mathbf{I}_{\text {in }} \\
{[\mathbf{A}]}\end{array}$ & $\begin{array}{c}\mathbf{V}_{\mathbf{o}} \\
{[\mathbf{V}]}\end{array}$ & $\begin{array}{c}\mathbf{I}_{\mathbf{o}} \\
{[\mathbf{A}]}\end{array}$ & $\begin{array}{c}\mathbf{W}_{\text {in }} \\
{[\mathbf{W}]}\end{array}$ & $\begin{array}{c}\mathbf{W}_{\mathbf{o}} \\
{[\mathbf{W}]}\end{array}$ & $\begin{array}{c}\text { Efficiency } \\
{[\%]}\end{array}$ \\
\hline \multirow{2}{*}{$\mathbf{2 8 \%}$} & $\mathrm{C}$ & 196.4 & 6.03 & 387.5 & 2.7 & 1184.29 & 1046.25 & 88.34 \\
& $\mathrm{P}$ & 201.4 & 5.4 & 387.5 & 2.53 & 1087.56 & 980.38 & 90.14 \\
$55 \%$ & $\mathrm{C}$ & 200.8 & 11.27 & 384.9 & 5.3 & 2263.02 & 2039.97 & 90.14 \\
& $\mathrm{P}$ & 196.5 & 11.27 & 386.2 & 5.3 & 22.14 .56 & 2046.86 & 92.43 \\
$76 \%$ & $\mathrm{C}$ & 198.7 & 15.57 & 386.6 & 7.32 & 3093.76 & 2829.91 & 91.47 \\
& $\mathrm{P}$ & 181.7 & 16.57 & 386.4 & 7.32 & 3010.77 & 2828.45 & 93.94 \\
$95 \%$ & $\mathrm{C}$ & 199.2 & 19.11 & 385.1 & 9.32 & 3806.71 & 3589.13 & 94.48 \\
& $\mathrm{P}$ & 189.9 & 19.86 & 384.4 & 9.45 & 3772.8 & 3642.03 & 96.53 \\
\hline
\end{tabular}

\section{Conclusions}

In this paper, the resonant ZVT boost DC-DC converter, which uses the auxiliary resonant circuit, is proposed. All switches of the proposed converter were operated under ZVS and ZCS. Thus, the switching losses were reduced by using the resonant circuit. It is composed of two switches, the resonant inductor and two resonant capacitors. Furthermore, the proposed converter reduces the conduction loss of the resonant inductor, compared to the conventional converter. As a result, the proposed converter improves the whole system's efficiency better than the conventional converter at the same frequency. To verify, the experiment was successful. The measured efficiency of the proposed converter is $96.5 \%$, which is a highly improved result, compared to the conventional resonant converter at $94.2 \%$. In addition, based on mathematical modeling, the equivalent circuit of each operation mode was analyzed. Operation modes were divided, considering the current and voltage waveforms. The simulation was performed to verify the validation of the proposed converter. To conclude, the simulation and experimental results were the same.

Therefore, the proposed high-efficiency converter is suitable for applications such as photovoltaic converters of DC distribution and sensor systems.

Author Contributions: Conceptualization, H.J.L. and Y.-H.K.; Formal Analysis, H.J.L.; Supervision, Y.-H.K.

Funding: This research received no external funding.

Conflicts of Interest: The authors declare no conflict of interest.

\section{Nomenclature}

$L_{m} \quad$ Main Inductor

$L_{r} \quad$ Resonant Inductor

$C_{r} \quad$ Resonant Capacitor

$C_{a} \quad$ Auxiliary Capacitor

$D_{0} \quad$ Output Diode

$S_{1} \quad$ Main Switch

$S_{2} \quad$ Auxiliary Switch 2

$S_{3} \quad$ Auxiliary Switch 3

$i_{\text {Lm }} \quad$ Main Inductor Current

$i_{L r} \quad$ Resonant Inductor Current

$v_{\mathrm{Cr}} \quad$ Resonant Capacitor Voltage

$v_{\mathrm{Ca}} \quad$ Auxiliary Capacitor Voltage

$i_{\text {Do }} \quad$ Output Diode Current 


\section{References}

1. Tsai, C.H.; Su, J.Y. A Soft-Switching SEPIC with Multi-Output Sources. Electronics 2017, 6, 35. [CrossRef]

2. Lin, B.-R. Investigation of a Resonant dc-dc Converter for Light Rail Transportation Applications. Energies 2018, 11, 1078. [CrossRef]

3. Lee, H.J.; Shin, S.C.; Hong, S.J.; Hyun, S.W.; Lee, J.H.; Won, C.Y. Performance Improvement of Isolated High Voltage Full Bridge Converter Using Voltage Doubler. J. Electr. Eng. Technol. 2014, 9, 2224-2236. [CrossRef]

4. Kim, Y.H.; Ji, Y.H.; Kim, J.G.; Jung, Y.C.; Won, C.Y. A New Control Strategy for Improving Weighted Efficiency in Photovoltaic AC Module-Type Interleaved Flyback Inverters. IEEE Trans. Power Electron. 2013, 28, 2688-2699. [CrossRef]

5. Kim, Y.H.; Jang, J.W.; Shin, S.C.; Won, C.Y. Weighted-Efficiency Enhancement Control for a Photovoltaic AC Module Interleaved Flyback Inverter Using a Synchronous Rectifier. IEEE Trans. Power Electron. 2014, 29, 6481-6493. [CrossRef]

6. Xue, J.; Lee, H. Enabling High-Frequency High-Efficiency Non-Isolated Boost Converters With Quasi-Square-Wave Zero-Voltage Switching and On-Chip Dynamic Dead-Time-Controlled Synchronous Gate Drive. IEEE Trans. Power Electron. 2015, 30, 6817-6828. [CrossRef]

7. Moshirvaziri, M.; Li, C.; Trescases, O. A quasi-resonant bi-directional tri-mode DC-DC converter with limited valley current. In Proceedings of the Twenty-Seventh Annual IEEE Applied Power Electronics Conference, Coronado, CA, USA, 5-9 February 2012; pp. 517-523. [CrossRef]

8. Liu, Y.C.; Chen, M.C.; Yang, C.Y.; Kim, K.A.; Chiu, H.J. High-Efficiency Isolated Photovoltaic Micro inverter UsingWide-Band Gap Switches for Standalone and Grid-Tied Applications. Energies 2018, 11, 569. [CrossRef]

9. Pilawa-Podgurski, R.C.N.; Sagneri, A.D.; Rivas, J.M.; Anderson, D.I.; Perreault, D.J. Very High Frequency Resonant Boost Converters. In Proceedings of the IEEE 38th Annual Power Electronics Specialists Conference, Orlando, FL, USA, 17-21 June 2007; pp. 2718-2724. [CrossRef]

10. Cheng, X.F.; Zhang, Y.; Yin, C. A ZVS Bidirectional Inverting Buck-Boost Converter Using Coupled Inductors. Electronics 2018, 7, 221. [CrossRef]

11. Urgun, S. Zero-voltage transition-zero-current transition pulse width modulation DC-DC buck converter with zero-voltage switching-zero-current switching auxiliary circuit. IET Power Electron. 2012, 5, 627-634. [CrossRef]

12. Mahesh, M.; Panda, A.K. High-power factor three-phase ac-dc soft-switched converter incorporating zero-voltage transition topology in modular systems for high-power industry applications. IET Power Electron. 2011, 4, 1032-1042. [CrossRef]

13. Phattanasak, M. A ZVT boost converter using an auxiliary resonant circuit. In Proceedings of the Power Electronics, Drives and Energy Systems, New Delhi, India, 12-15 December 2006; pp. 1-6. [CrossRef]

14. Khorasani, R.R.; Adib, E.; Farzanehfard, H. ZVT Resonant Core Reset Forward Converter with a Simple Auxiliary Circuit. IEEE Trans. Ind. Electron. 2018, 65, 242-250. [CrossRef]

15. Park, S.H.; Park, S.R.; Yu, J.S.; Jung, Y.C.; Won, C.Y. Analysis and design of a soft-switching boost converter with an HI-bridge auxiliary resonant circuit. Trans. Power Electron. 2010, 25, 2142-2149. [CrossRef]

16. Han, D.W.; Lee, H.J.; Shin, S.C.; Kim, J.G.; Jung, Y.C.; Won, C.Y. A new soft switching ZVT boost converter using auxiliary resonant circuit. In Proceedings of the IEEE Vehicle Power and Propulsion Conference, Seoul, Korea, 9-12 October 2012; pp. 1250-1255. [CrossRef]

17. Mercorelli, P.; Werner, N. An Adaptive Resonance Regulator Design for Motion Control of Intake Valves in Camless Engine Systems. IEEE Trans. Ind. Electron. 2017, 64, 3413-3422. [CrossRef]

18. Schimmack, M.; Costa, M.L.; Mercorelli, P. Comparing Two Voltage Observers in a Sensorsystem using Repetitive Control. IFAC-PapersOnLine 2016, 49, 7-11. [CrossRef]

19. Bodur, H.; Bakan, A.F. A new ZVT-PWM DC-DC converter. IEEE Trans. Power Electron. 2002, 17, 40-47. [CrossRef]

20. Aksoy, I.; Bodur, H.; Bakan, A.F. A new ZVT-ZCT-PWM DC-DC converter. IEEE Trans. Power Electron. 2010, 25, 676-684. [CrossRef]

21. Lee, D.Y.; Lee, M.K.; Hyun, D.S.; Choy, I. New Zero-Current-Transition PWM DC/DC Converters without Current Stress. IEEE Trans. Power Electron. 2002, 18, 95-104. [CrossRef] 